\title{
Toxopathological and immunotoxical effects of thiamethoxam in white mice
}

\author{
A.R. Dirwal M.J. Alwan A.B. Falih
}

Coll. of Vet .Med -Univ. of Baghdad

\section{Abstract}

In order to investigate toxopathological and immunotoxic, effects of thiamethoxam in mice. Forty eight white mice, both sexes were divided into four groups equally, 1st group was immunized twicely with Brucella melitensis Rev1.with two weeks intervals. $2^{\text {nd }}$ group was immunized as in the $1^{\text {st }}$ group and at same time administrated orally with $83.73 \mathrm{mg} \backslash \mathrm{kg} \mathrm{B}$.W of thiamethoxam daily for 6 weeks. $3^{\text {rd }}$ group was administrated with thiamethoxam as in the $2^{\text {nd }}$ group while the $4^{\text {th }}$ group was served as control negative group. Immunological examination DTH and humoral immunity revealed that the thiamethoxam induced depressed in both arms of immune response as comparing with vaccinated non-treatment animals. The pathological examination revealed that the thiamethoxam induced, necrosis, hypertrophy of hepatocytes with multiple granulomatous lesion scatter in liver parenchyma and these lesions were progressive with period time particularly at 6 weeks post-treatment that showed marked proliferation of hepatocytes. The electron microscope examination to liver section showed lipid droplet, proliferation of mitochondria enlargement in addition to distraction of nuclear membrane and presence facular space, also there was severe hemorrhage in the renal interstitial tissue with inflammatory cells infiltration together with fibrosis of the glomeruli wall. Congestion with inflammatory cells infiltration in the red pulp of spleen, in addition to gliosis in the brain parenchyma was seen . The immunized animals showed mild pathological changes characterized by aggregation of mononuclear cells, The electron microscope to liver section showed normal organelles cell. with lymphoid hyperplasia in the spleen and in subepithelial layer of intestinal mucosa. We concluded that thiamethoxam induced toxopathological changes in the internal organs of mice and stimulated the immune response diminished its toxic effects.

Key words : thiamethoxam, toxopathological, immunotoxical.

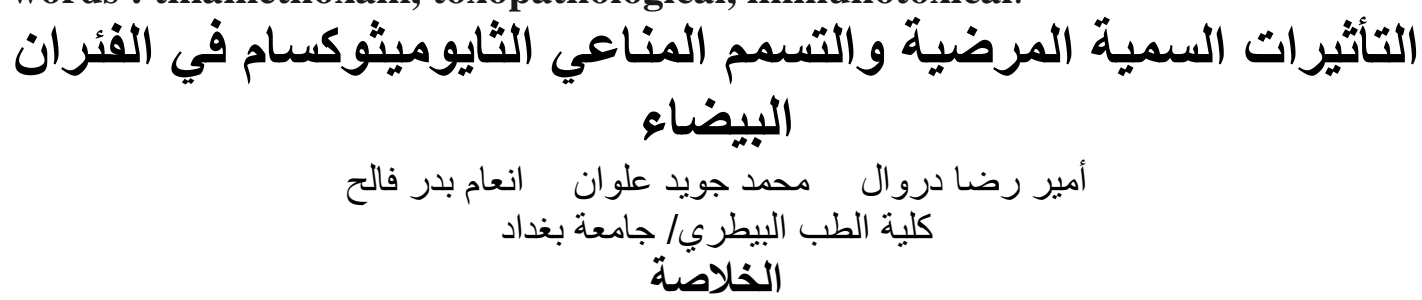

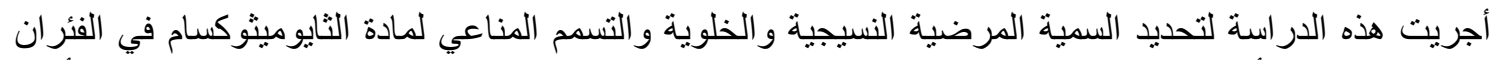

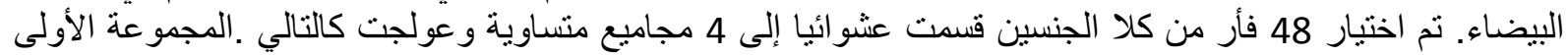

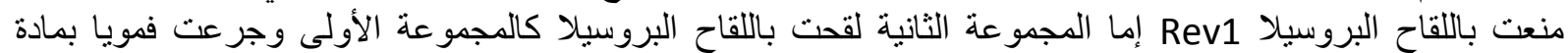

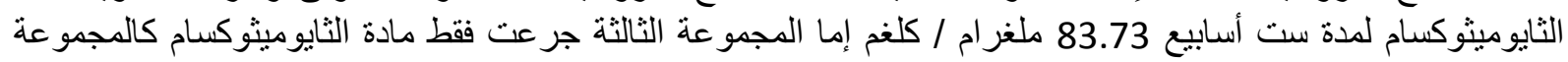

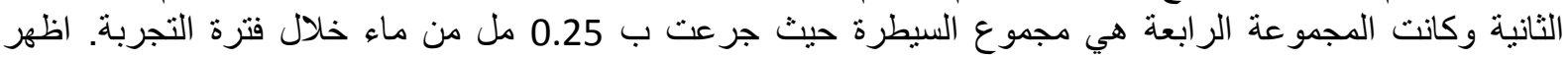

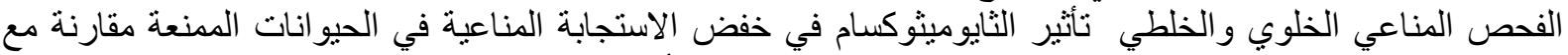

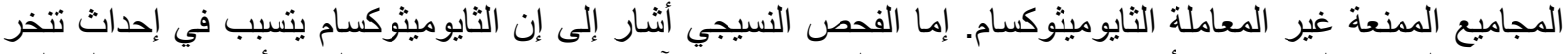

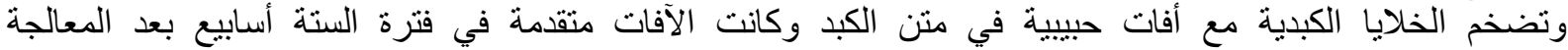

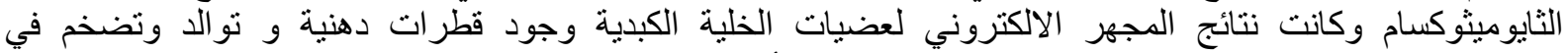

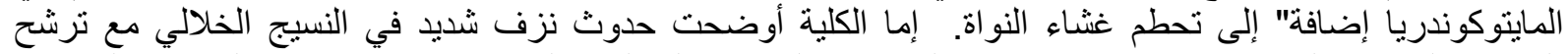

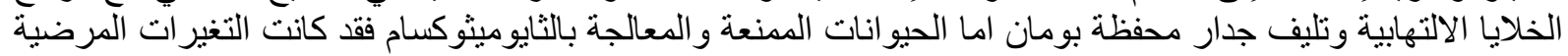

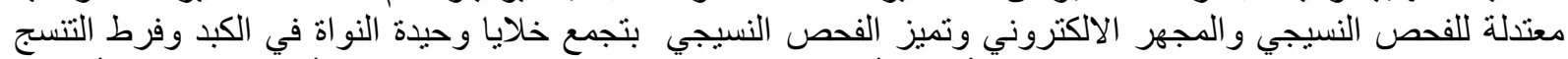

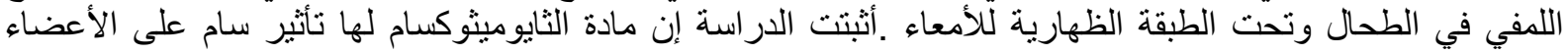
الداخلية وانخفاض الاستجابة المناعية في الفئران. الكلمات المفتاحية: التأثيرات السمية المرضية في التئة ، التسمم المناعي ، الثايوميثوكسام ، الفئران البيضاء. 


\section{Introduction}

Neonicotinoid insecticides were introduced into the market in the early 1990s, and are today one of the most important chemical groups used to control sucking insects (1).These insecticides currently make up about $25 \%$ of the global insecticide market with the two major compounds being thiamethoxam and imidacloprid (2). Thiamethoxam is first example of second generation neonicotinoids, is systemic insecticide for soil and foliar applications and controls a broad range of commercially important sucking and chewing pests (3).and also with others neonicotinoids act as agonists at the insect nicotinic acetylcholine receptor (nAChR), however The neonicotioids generally have favorable mammalian toxicology with the exception of thiamethoxam which is a hepatotoxicant and hepatocarcinogen in mice but not rats or dogs(4).Thiamethoxam, a standard inhibitory inducible nitric oxide synthase, an enzyme with regulatory role in the development hepatotoxicity (5). A comprehensive genotoxicity assessment (including bacterial mutagenicity, gene mutation, cytogenetic, unscheduled DNA synthesis, and mouse micronucleus tests) demonstrated that thiamethoxam was not genotoxic. It did, however, cause an increased incidence of liver tumors in male and female. One of the metabolites, CGA322704, has previously been tested for carcinogenicity in CD-1 mice(6) Metabolite CGA265307 was found to be structurally similar to known inhibitors of inducible nitric oxide synthase (7). There was little literature concerning pathological and immunotoxic effects of thiamethoxam insecticide in Iraq therefore the aim of this study is to investigate the pathological and
Immunotoxic of ${ }^{1} \backslash_{10 L D 50}$ of thiamethoxam insecticide in mice.

\section{Materials and methods}

1- Insecticide Thiamethoxam $25 \%$ WS (Actara) Chemical name: 3-[(2-chloro-5thiazolyl) methyl] tetrahydro-5-methyl-Nnitro-4H-1，3，5Noxadiazin-4 imine. this insecticide dissolved with water, Thiamethoxam has an acute oral $\mathrm{LD}_{50}=837.5 \mathrm{mg} \mathrm{kg} \mathrm{b.w}$ for white mice (8).

2- Experimental Animals: Forty eight white mice of 7-8 weeks in age, supplied from animal house were used in this study the animal were divided into four groups (10 mice for each group) and were treated as following:

$1-1^{\text {st }}$ group was immunized with Brucella melitensis Rev1, two doses, with two weeks intervals.

$2-2^{\text {nd }}$ group was immunized as in $1^{\text {st }}$ group and at the same time It was given daily thiamethoxam, via oral route, $\left.{ }^{1}\right\rfloor_{\mathbf{1 0}} \mathbf{D}_{\mathbf{5 0}}$, equaled to $83.73 \mathrm{mglkg}$, b.w for 6 weeks.

$3-3^{\text {rd }}$ group was administrated with thiamethoxam as in $2^{\text {nd }}$ group.

4- $4^{\text {th }}$ group was administrated daily with $0.25 \mathrm{ml}$ of sterile normal saline orally for 6 weeks and it was served as control negative group.

\section{Results}

\section{1-Results Immunological examination}

Skin test: At $24 \mathrm{hr}$. post testing, the results showed that the mean values of skin thickness against Brucelin was high in $1^{\text {st }}$ group ( $0.39 \pm 0.07)$ as comparing with $2^{\text {th }}$ group $(0.7 \pm 0.01)$ and these values were increase at $48 \mathrm{hr}$ post-examination in the $1^{\text {st }}$ group $(0.42 \pm 0.08),, 2^{\text {nd }} \operatorname{group}(0.27 \pm 0.14)$ but these values were declined at $72 \mathrm{hr}$ postexamination.

Table (1) values skin test in immunized groups at 24 and 48 hours. (measured in mm).

\section{L.S.D $=0.13$}

\begin{tabular}{|c|l|cc|cc|}
\hline Group & \multicolumn{1}{|c|}{ Group } & \multicolumn{2}{|c|}{24 mean \pm m } & \multicolumn{2}{|c|}{48 mean SE } \\
\hline 1 & Brucella vaccine & $0.39 \pm 0.07$ & A & $0.42 \pm 0.08$ & B \\
\hline 2 & $\begin{array}{l}\text { Thiamethoxam }+ \\
\text { B. vaccine }\end{array}$ & $0.7 \pm 0.01 \quad$ bB & $0.27 \pm 0.14$ & aC \\
\hline
\end{tabular}

The results of passive haemagglutination examination in the 2 weeks revealed that the serum Abs titers in $1^{\text {st }}$ group was $(160+32)$ higher than $2^{\text {nd }}$ group $(10 \pm 2)$, while these values at 30 days the serum Abs titers in $1^{\text {st }}$ group $(320 \pm 64)$ was higher than $2^{\text {nd }}$ group

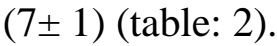


Table: 2. values serum Ab titers at 14 and 30 days post-immunized animals

\begin{tabular}{|c|c|cc|cc|}
\hline Group & Group & 2 weeks & mean \pm SE & 4 weeks & mean \pm SE \\
\hline 1 & Brucella vaccine & $160 \pm 32$ & bB & $320 \pm 64$ & aB \\
\hline 2 & Thiamethoxam + B. vaccine & $10 \pm 2$ & $\mathrm{C}$ & $7 \pm 1$ & $\mathrm{C}$ \\
\hline
\end{tabular}

L.S.D $=77.13$

\section{2- Histopathological examination:} Animals dosages thiamethoxam *2 weeks post-treated with thiamethoxam1. Liver :the main lesions in the liver characterize by small granulomatous lesions in the liver parenchyma consisting from aggregation of activated macrophage and lymphocytes in addition to hypertrophy of some hepatocytes which lead to occlude of sinusoid as well as vacuolar degeneration and necrosis of hepatocytes that showed pyknotic or disappeared of their nuclei (Fig. 1).

2.Kidney: It showed inflammatory cell infiltration particularly macrophage and neutrophils around the blood vessels as well as fibrosis of bowman capsule wall of the glomeruli (Fig. 2).

3.Intestine the microscopic section of the intestine showed neutrophils aggregation in the lamina properia of the villa with goblet cell hypertrophy and hyperplasia in addition to erosion of epithelial lining cells. Other section mucin and neutrophils were seen in the lumen of the intestine (Fig. 3).

*4 weeks post- treated with thiamethoxam

1.Liver: microscopic examination of the liver revealed complex granulomatous lesions consisting from necrotic center surrounding by macrophages ,lymphocytes and thick fibrous connective tissue capsule (Fig. 4). in addition to mononuclear cells aggregation mainly in the portal area around portal veins and bile duct. Other section, PMNs and mononuclear cells present in the dilated and congested central veins and sinusoids.

2.Spleen: the pathological picture of the spleen showed congested blood vessels with mononuclear cells in their lumen and depletion of white pulp as well as proliferation of megakaryocytes.
3.Intestine: microscopic section of the intestine showed hyperplasia of lymphoid tissues between mucosal glands (Fig.5) together with hyperplasia of goblet cells.

4.Brain: the pathological lesion in brain characterize by proliferation of astrocytes gliosis (Fig. 6).

5.Kidney; there are mononuclear cells particular macrophages and lymphocytes aggregation in the necrotic area that seen around glomeruli which showed dilated renal bowman's capsule with Taft vacuolation (Fig. 7), in addition to hemorrhagic area in the interstitial tissue vacuolar degeneration of epithelial lining cells of renal tubules. Increase thickness of glomerular wall, due to fibrosis and inflammatory cells infiltration mainly mononuclear cells, was seen The adipose tissues expressed congestion of blood vessels with neutrophils in their lumen as well as hemorrhage and neutrophils infiltration.

*6-Weeks post- treated with thiamethoxam1.

Liver: present of necrotic area of hepatocytes characterize by pyknotic or disappear of the nuclei and proliferation of kupffer cells as well as proliferation of hepatocytes that form pseudo lobule without central vein and clear sinusoids (Fig. 8), in other animal, the liver expressed large granulomatous lesion consisting from aggregation of epithelioid cells ,macrophages and lymphocytes surrounded by necrosis of hepatocytes.

2.Brain: expressed lesions were similar to those reported in 4weeks.

3.Kidney: Congestion of blood vessels and severe acute cellular degeneration characterized vacuolation, sloughing and desquamation of the epithelial lining cells of renal tubules. 


\section{Immunized animals}

*2 weeks treated with thiamethoxam

Liver: No clear lesions were seen in the liver except proliferation kupffer cell (Fig. 9) as well as mononuclear cells aggregation in the liver parenchyma and around central veins and in portal area were reported.

Spleen: The spleen exposed proliferation of lymphocytes in periarteriolar sheath and proliferation of mononuclear cells around sinus in red pulp form cord-like appearance (Fig. 10).

Kidney: No clear lesions were seen in the kidney.

Intestine: The intestine showed lymphoid tissue hyperplasia between mucosal glands (Fig. 11).

Brain: No clear lesions were seen in the brain.

*4 weeks post- treated with thiamethoxam Liver: The main lesion characterized by marked aggregation of mononuclear cells particularly lymphocyte around the central vein and proliferation and hypertrophy kupffer cell, in another section small granulomatous lesion consisting from aggregation lymphocyte and macrophage were recorded

Intestine: There is marked hyperplasia of lymphoid tissue between the mucosa gland which express and hypertrophy of goblet cell.

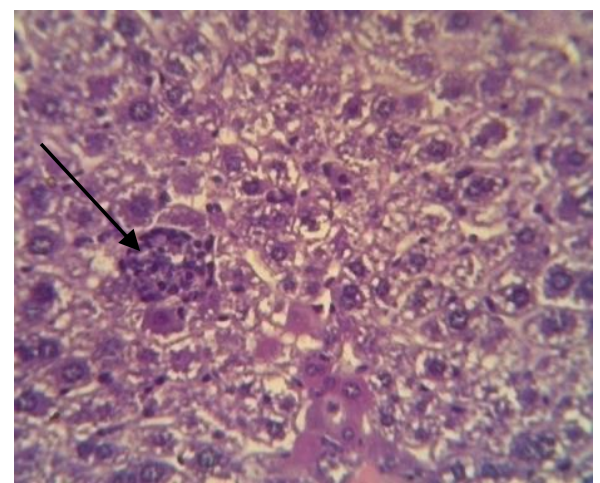

Fig: 1. Histopathological section in the liver of animal at 2 weeks post-treatment with thiamethoxam shows granulomatous lesion consisting from aggregation of mononuclear cells $\longrightarrow$ in addition to vacuolar degeneration and necrosis of hepatocytes (40X H\&E).
No clear lesions were seen in the kidney and brain

*6 weeks post- treated with thiamethoxam There are no clear lesion in the liver except proliferation of kupffer cells (Fig. 12) and other examined organs showed few mononuclear cells aggregation around blood vessels

\section{transmission electron microscope (T E M)}

A-Control group The electron microscope examination to liver mouse control showed normal mitochondria with normal endoplasmic reticulum in addition to normal nuclear member and nucleus (Fig.13) .

B-Thiamethoxam group The electron microscope examination in the liver section of orally gavaged with thiamethoxam showed lipid droplet proliferation, mitochondria enlargement of cristae fuse together, degenerative changes in mitochondria swelling in addition to distraction of nuclear membrane and presence facular space (Fig.14). In addition deposition of black spot and degeneration with dilatation of intracellular space (Fig. 15).

C- thiamethoxam + vaccine group The electron microscope to liver section mouse orally gavaged with thiamethoxam and inoculated with $B$. melitensis Rev 1 vaccine showed chromatin mass against nuclear membrane and normal rough endoplasmic reticulum and normal nuclear and mitochondria (Fig.16).

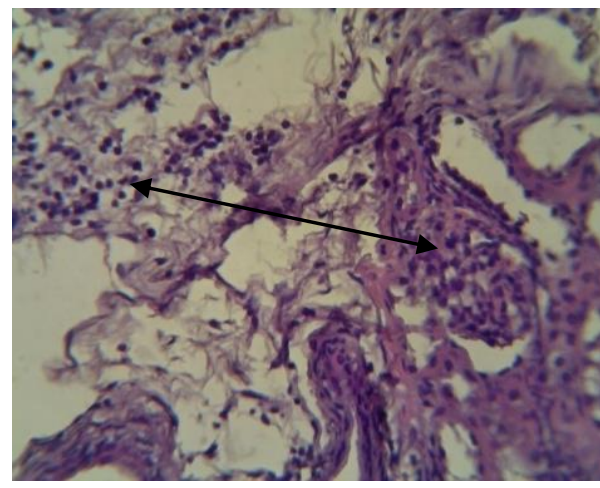

Fig: 2. Histopathological section in the kidney of animal at 2 weeks post-treatment shows inflammatory cells infiltration particularly macrophage and neutrophils around the blood vessels as well as fibrosis of the bowman capsule wall $\longleftrightarrow$ (40X H\&E) 


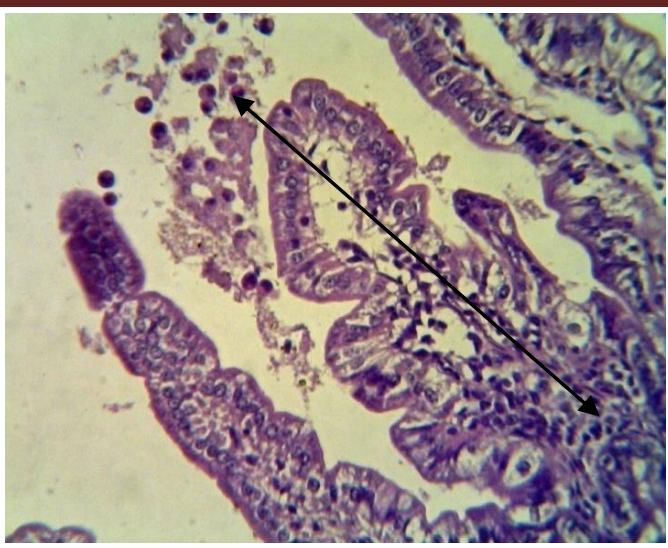

Fig:3. Histopathological section in the intestine of animal at 2 weeks post-treatment shows inflammatory cells infiltration particularly neutrophils in the lamina properia of villa and in the lumen of the intestine $\longleftrightarrow$ together with mucin apperance $(40 \mathrm{X} \mathrm{H \& E})$.

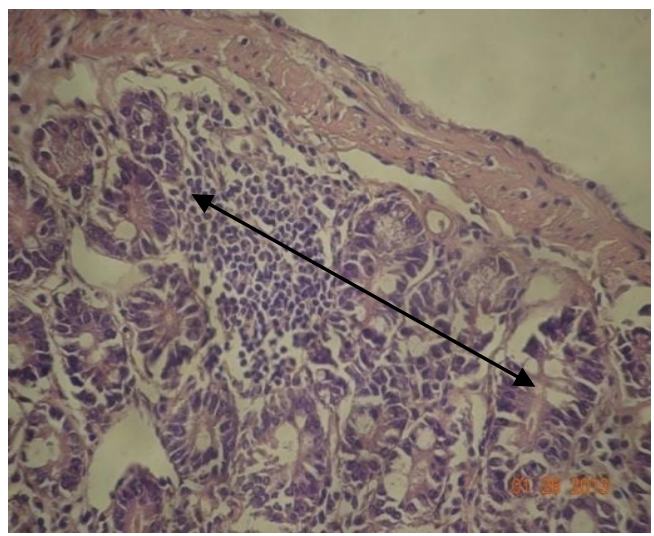

Fig: 5 Histopathological section in the intestine of animal at 4 weeks post-treatment shows hyperplasia of lymphoid tissues between mucosal glands $(\mathrm{H}$ \&E stain 40X )

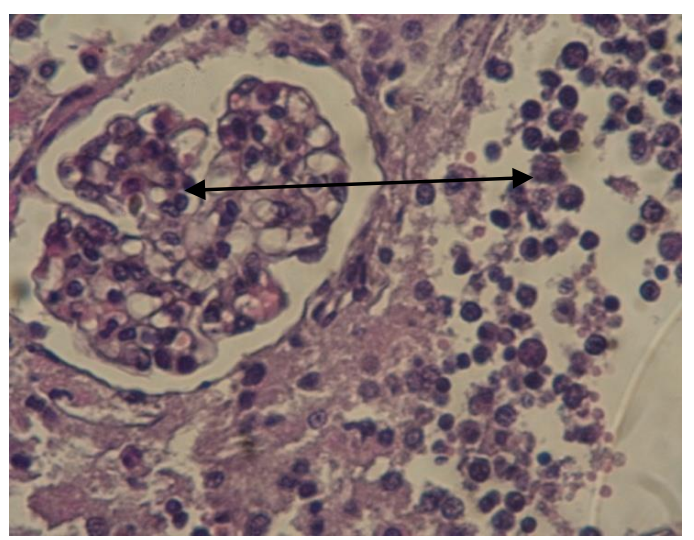

Fig:7. Histopathological section in the kidney of animal at 4 weeks post-treatment shows vacuolation of glumerular tufts, and macrophages aggregation in necrotic area around glumerula $\longleftrightarrow$ (40X H\&E).

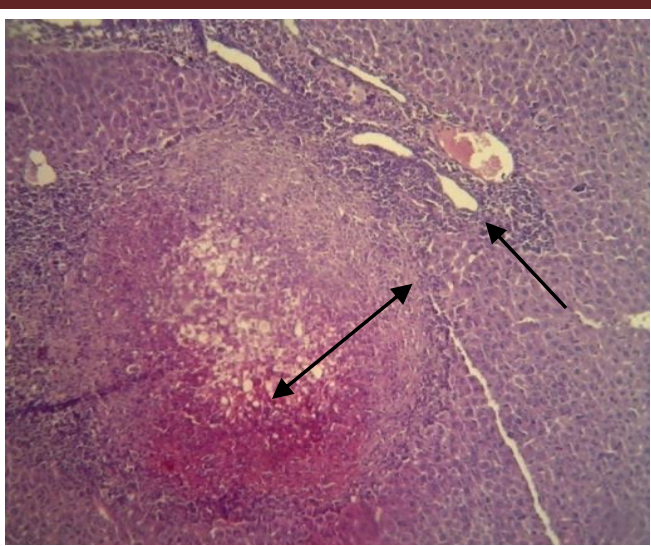

Fig:4.Histopathological section in the liver of animal at 4 weeks post-treatment shows complex granulomatous lesion consist from necrosis in the center surrounding by macrophages, lymphocytes and thick fibrosis connective tissue capsule $\longleftrightarrow$, in addition mononuclear cell aggregation around the blood vessels in the portal area around portal vein and bile duct $\longrightarrow$ (100X H\&E)..

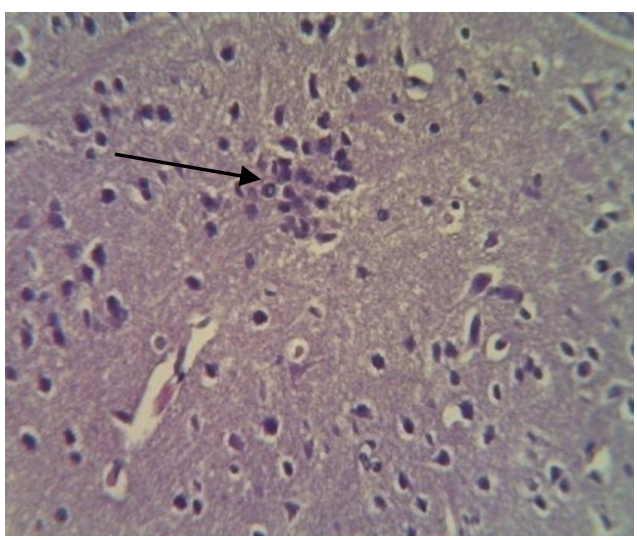

Fig:6 Histopathological section in the brain of animal at 4 weeks post-treatment shows gliosis $\rightarrow(40 \mathrm{X} \mathrm{H \& E})$.)

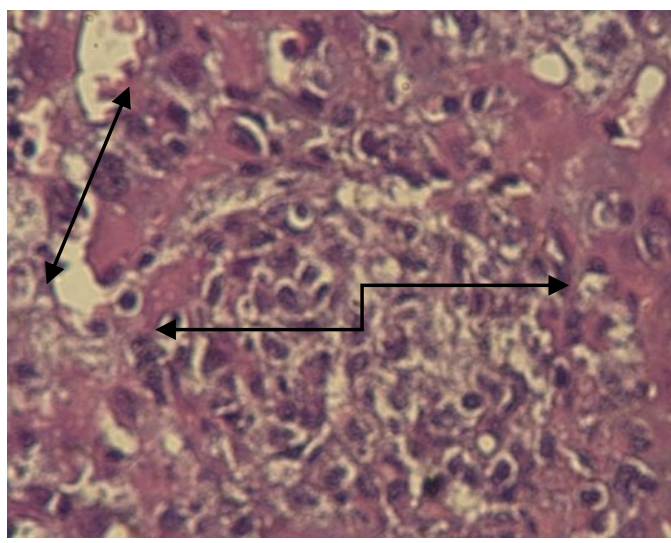

Fig:8 Histopathological section in the liver of animal at 6 weeks post-treatment shows large granulomatous lesion consisting from aggregation of epithelioid cells, macrophages and lymphocytes surrounded by necrosis of hepatocytes $\longleftrightarrow$ and congested dilated central vein and sinusoids $\longleftrightarrow$ (40X H\&E). 


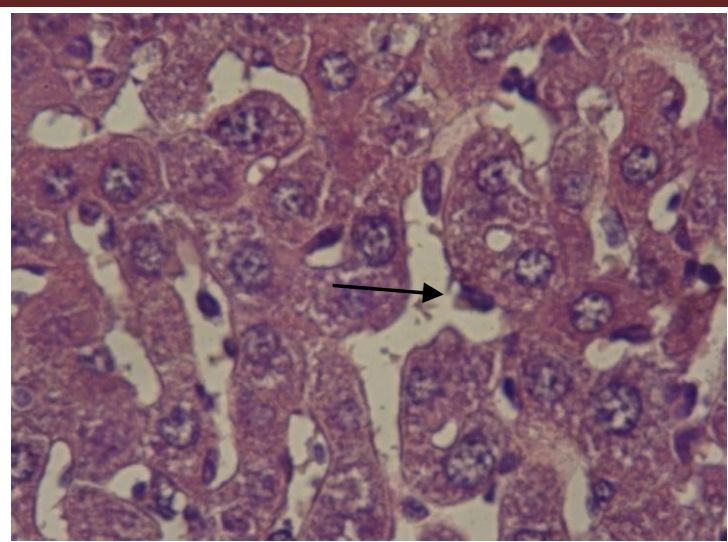

Fig: 9.Histopathologcal section in the liver of immunized animal at 2 weeks post-treated with thiamethoxam shows no clear lesions except proliferation and hyper atrophy of kupffer cell $\rightarrow$ (40X H\&E).

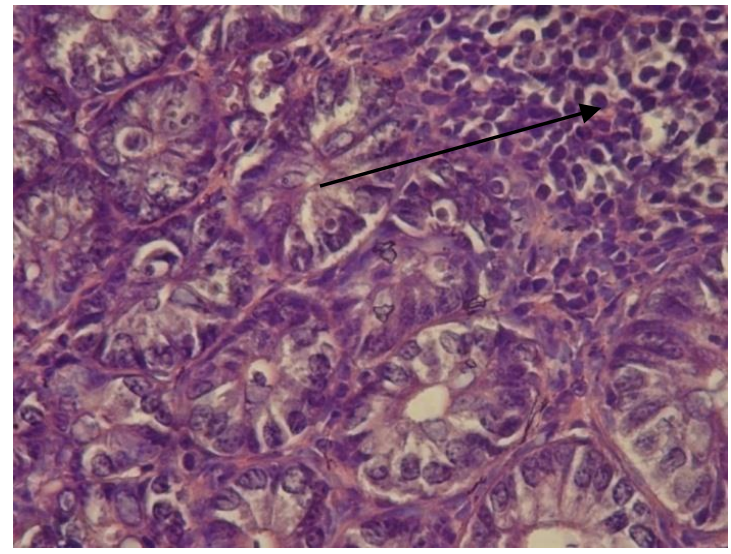

Fig:11.Histopathologcal section in the intestine of immunized animal at 2 weeks post-treated with thiamethoxam shows lymphoid tissue hyperplasia $\longrightarrow$ (40X H\&E).

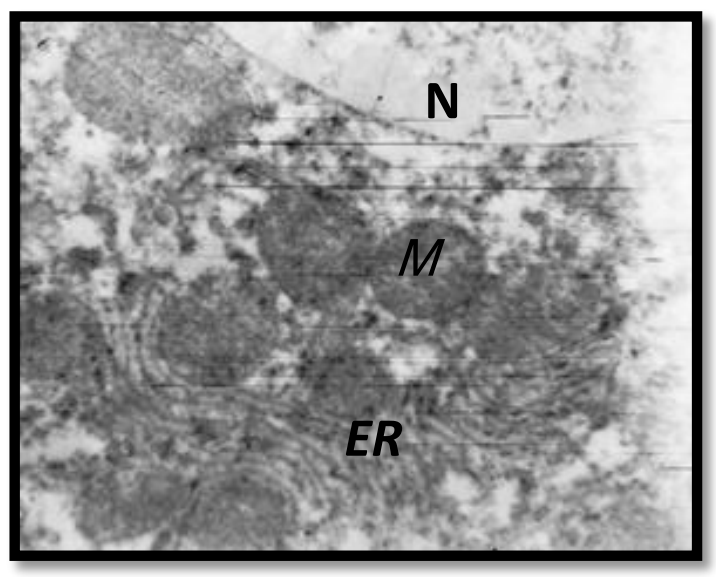

Fig: 13 Electron micrograph showing a mouse liver (control). normal nucleus $(N)$, mitochondria $(M)$ with normal rough endoplasmic reticulum ( $E R$ ) in addition to normal nuclear membrane

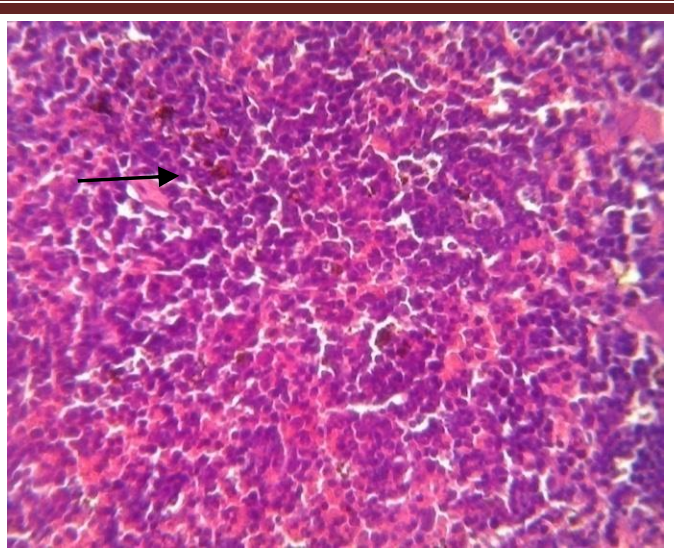

Fig:10.Histopathologcal section in the spleen of immunized animal at 2 weeks post-treated with thiamethoxam shows proliferation of lymphocytes in the periarteriolar sheath $\longrightarrow$ (40X H\&E).

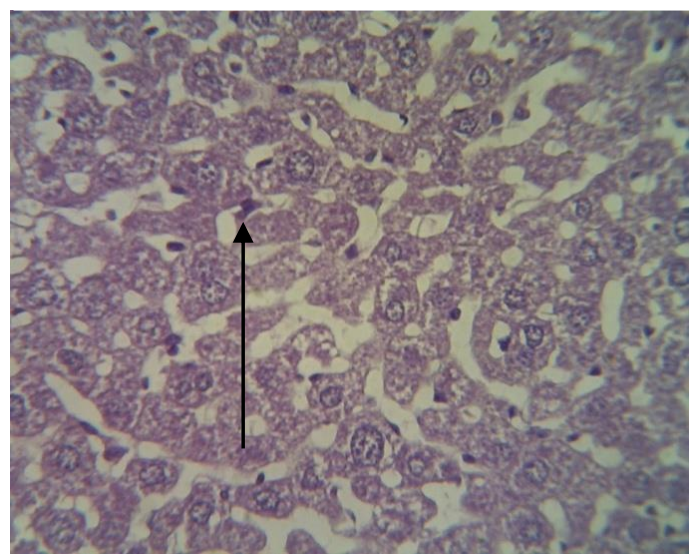

Fig:12 Histopathological section in the liver of immunized animal at 6 weeks post -treated with thiamethoxam shows proliferation of kupffer cells $\longrightarrow$ (40X H\&E).

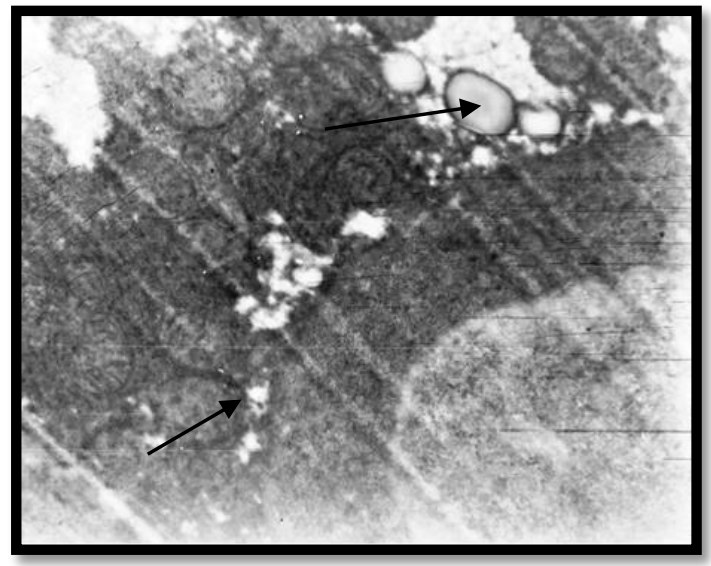

Fig: 14 The electron microscope examination to liver section mouse orally gavaged with thiamethoxam showed lipid droplet, proliferation of mitochondria enlargement of crystae fuse together degenerative changes in mitochondria swelling in addition to distraction of nuclear membrane and presence facular space 


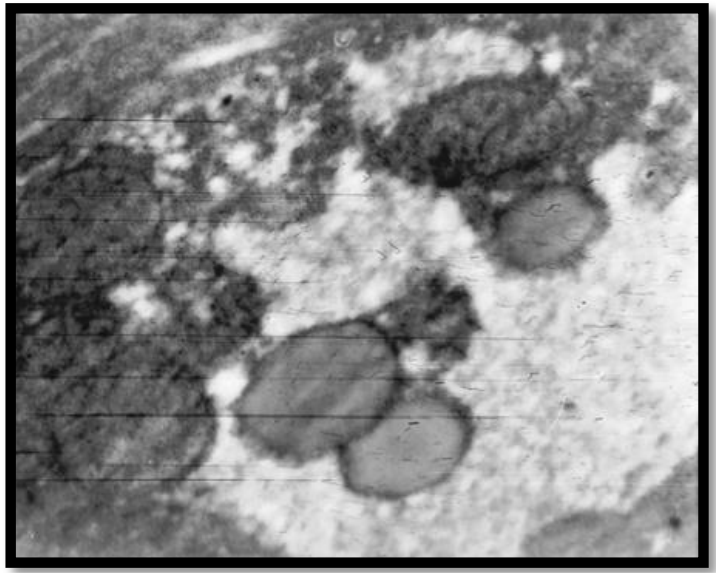

Fig: 15 The electron microscope examination to liver section mouse orally gavaged with thiamethoxam showed enlargement of mitochondria fuse together deposition of black spot and degeneration dilatation intracellular space

\section{Discussion}

The current demonstration showed that immunized animals-treated with TMX expressed mild pathological changes, these result may be due to stimulated immune response diminished the toxic effects of the TMX. Immunotoxicity is a relatively new field, a considerable amount of data has accumulated during the past few year on immunotoxicity of certain xenobiotic, and the majority of the research by that for carried out has been on environmental contamination (25) many Xenobiotices have capacity to induce or inhibit the co stimulatory molecule due to their intrinsic adjuvant activity(25),on base on above information, it was suggested that immunized animals elicited a good immune response that activated the macrophage and increase its ability to produce co-stimulatory molecules ,also the activated immune responses increase production of inducible Nitric oxide synthatase which inhibited by TMX (5) , therefore ,elicited immune response may abolished the toxic effects of TMX. The proliferation of kupffer cells and hyperplasia of lymphoid tissue in the current study may be due to stimulated immune response (26) and due to decrease cytotoxicity of TMX these evidence was supported idea mention by certain authors, TMX irreversible bind to acteycholinestrase that normally catalyzes the hydrolysis of acetycholine $\mathrm{ACH}$ at the cholinergic

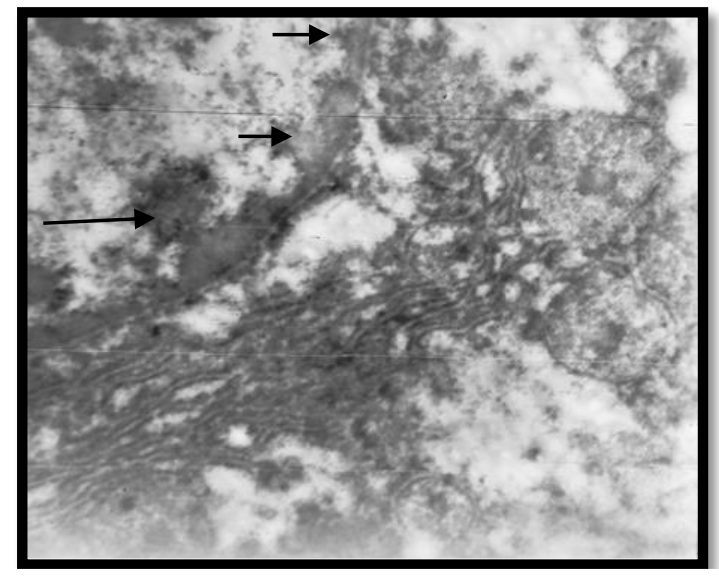

Fig:16 The electron microscope to liver section mouse orally gavaged with thiamethoxam and inoculated with $B$. mltencesis Rev 1 vaccine showed chromatin mass $\rightarrow$ against nuclear membrane and normal rough endoplasmic reticulam and normal nuclear mitoconderia

synapses and neuromuscular junction, thus result in accumulation of acetylcholine in the cholinergic synapse and lead to immunosuppressant (27), according to above observation, it was suggested that activated immune response may be prevent action of TMX on acetylcholinestrase. The present study showed different pathological lesions in the liver, increasing its severity within a period of time. the main lesions, at 2 weeks post-treatment are vacuolar degeneration with enlargement of hepatocytes which causes of narrowing or occluded of sinusoidal hepatocytic cells in the liver, these result may be indicated that the liver tissue are more susceptible to cytotoxic effect of thiamethoxam and displayed clear pathological changes such as hyperplasia and hypertrophy. The center detoxifying of any foreign materials such toxins and chemical substances that entering to the body is the liver (15). The present study was agreement with (16) who showed disturbed hepatic lobule, hydropic degeneration, vacuoles in the cytoplasm of hepatocytes of liver of rat treated with thiamethoxam as well as, pyknotic or karyolytic nuclei of hepatocytes. Also (17) found that the liver of rats treated with diflubenzuron, cypermethrin and fenitrothion expressed cloudy swelling, hydropic degeneration, while previous observation by (18) recorded hepatocellular hypertrophy, hyperplasia and enlargement of hepatic blood space at 3 weeks post-treated 
of rats with Phenobarbital. The present study showed hypertrophy of hepatocytes may be due to increase in number and size of rough endoplasmic reticulum and smooth endoplasmic reticulum as shown by electron microscopy in this study. Appearance of granulomatous lesions that recorded in the liver of this present study may due to necrosis of hepatocytic cells as a result of enlargement of hepatocytes that occluded the sinusoids and blood vessels, these result was approximately similar to the observations of (19) which found that in some xenobiotics, the toxicity associated with vascular occlusive changes that lead to reduce sinusoidal blood circulation, hypoxia ,necrosis and granulomatous inflammation. The present study demonstrated evidence of extensive of hepatocellular necrosis at 4-6 weeks post-treatment with multiple complex granulomatous lesions scatter in the liver parenchyma, these result may due to metabolic activation forming from thiamethoxam that lead to more toxic effect on hepatic cells, in addition the present result expressed proliferation of hepatocytic cells particularly at 6 weeks post-treated in which there are pseudo lobules, these observation may indicated that the thiamethoxam stimulated hepatocellular replication ,these results were correlated with the result of electron microscopic examination that showed enlargement of mitochondria and increase in peroxisome proliferation with fatty droplet in the hepatocytes this observation was consistent with (5) who explained that rat fed diet supplement with thiamethoxam showed liver toxicity including single cell necrosis and an increase in apoptosis and a significant increase in hepatic cell replication rates after 20 weeks.(20) recorded that the histomorphological changes in hepatoxic liver include fluid accumulation, fatty change in hepatocytes, inflammatory cell infiltration, fibrosis, and possibly granuloma formation also (21) administrated that Prolonged hepatotoxicity with associated regenerative hyperplasia can be associated with and lead to liver tumor development also Metabolites in some cases contribute to mammalian hepatotoxicity and carcinogenesis of pesticides. However, the pathological changes in the internal organs particularly liver may due to toxic effects of thiamethoxam metabolites, these evidence was supported idea (5) who found that metabolite CGA330050 induced hepatotoxic. The present findings revealed different pathological lesions in the Kidneys may be due to the kidney are an important excretory organ, which, along with the liver, also accumulate toxicants. Chemically induced injury to the kidneys is reported to occur as a result of the direct effect of thiamethoxam or a metabolite on renal cells, or it occurs indirectly by alteration in renal hemodynamics, or by a combination of both. The present investigation showed inflammatory cells particularly neutrophils and mononuclear cells aggregation around blood vessels between renal tubules in addition to fibrosis in the wall of the glomeruli, these lesions may be due to inhibiting of intracellular proteins activities and others, and finally metabolic poisoning with death of cell (22). The present study showed narrow of glomerular space due to hyper cellularity of the glomeruli at two weeks post-treatment. These result was similar to those reported by (16) who reported narrow urinary spaces or hyper cellularity of the glomeruli as well as Cloudy swelling in the renal tubules, desquamation of the epithelial cells of some tubules and the nuclei of many of the tubules was disappeared. Also The renal lesions in the present study was consistence with The histopathological lesions obtained from the (16) who reported, treated rats showed hemorrhagic areas in the interstitial space between the tubules and glomeruli. Also (17) reported that treated rats (with cypermethrin, permethrin and fenvalerate) kidneys showed different phases of degenerative changes in the form of cloudy swelling, hydropic degeneration and detached cells The hemorrhage that recorded in the kidney may be due to decline in the level of Nitric oxide ,a vascular protective factor, as a result of effecting of TMX on Nitric oxide synthatase, this investigation was consistence with (5) who explained that the toxicity of metabolite of TMX,dm-TMX 
exacerbated by dm-CLO and iNOS inhibitor also (5) found that metabolite CGA265307 was shown to be an inhibitor of inducible nitric oxide synthatase. Nitric oxide synthatase is an enzyme that generates the vasoprotective molecule nitric oxide(NO) which released toward the vascular lumen and inhibited of platelets aggregation and adhesion (23). NO. also can inhibit leukocyte adhesion to the vessel wall either by interfering with the ability of the leukocyte adhesion molecule CD11/CD18 to form an adhesive bond with the endothelial cell surface or by suppressing CD11/CD18 expression on leukocytes, therefore, NO. may protect against the onset of atherogenesis. Also NO has been shown to inhibit DNA synthesis, mitogenesis, and

\section{References}

1.Yamamoto, I. and Casida JE, ( 1999). Nicotinoid Insecticides and the Nicotinic Acetylcholine Receptor. Springer-Verlag, Tokyo. ; p. 300 pp.

2.Jeschke, P., Nauen, R., Schindler, M., Elbert, A., (2011). Overview of the status and global strategy for neonicotinoids. Journal of Agricultural and Food Chemistry59, 2897-2908.

3.Maienfisch P.; L. Gsell and Rindlisbacher A., 1999). Synthesis and insecticidal activity of CGA 293343 a novel, broad spectrum insecticide. Pestic Sci.; 55: $351-355$.

4.Tomizawa, M., Casida, J.E., ( 2005). Neonicotinoid insecticide toxicology: mechanisms of selective action. Annual Review of Pharmacology and Toxicology 45, 247-268.

5. Green T, Toghill A, Lee R, Waechter F, Weber E, Noakes J (2005). Thiamethoxam induced mouse liver tumors and their relevance to humans. Part 1: mode of action studies in the mouse. Toxicol Sci $86,36-47$.

6.Federal Register (2003). Clothianidin; Pesticide Tolerance. Federal Register, May 30th, Vol. 68, No. 104

7.Brennan, P. A., and Moncada, S. (2002). From pollutant gas to biological messenger: The diverse actions of nitric oxide in cancer.Ann. R. Coll. Surg.Engl.84,75-78.

8.Anonymous. The e-Pesticide Manual. ( 2005 )(B. C. P. C.) The British Crop Protection Council Software Developed by Wise and Loveys Information Services Ltd.

9.Ramzi, S.C.; Vinay, K.; Stanley, R. (1994). Pathologic basis of diseases. Philadelphia: WB Saunders Company,. v.5, p.86.

10.Newcombe, DS and Esa,AH (1992) Immunotoxicity of organophosphorus compounds.In clinical immunotoxicity mDSM Newcombe, Rosem NR; Bloon, JC ed,PP349. 360.Raven.Press, New York. proliferation of vascular smooth muscle cells. (23) The pathological lesions were recorded in the intestine may be due the direct effects of thiamethox intestinal mucosa which lead to stimulate goblet cells to produce large amount of mucin in order remove or dilated the effects of TMX. The present finding showed that the TMX have toxic effects on the spleen and brain, these results were agreement with,(16) who reported that examination of sections of spleen of the treated rats that treated with TAM showed congestion and hemorrhagic area, also (24) showed congestion,, degeneration and large lymphoietic follicles and, necrosis in spleen tissues of albino rats treated with calciferol rodenticide.

11.Pruett,SB;Hany, $\mathrm{Y}$;Manson, $\mathrm{AF}$ and Fuch, AB, (2004).Assessiment of cholleinergic influence on a primary humoral immune response. Immunol. 77:428-432.

12.Szdeleny, JG; Bartha, EA and Hollan,R, (1998). cetylcholinestrase activity of lymphocytes, an enzyme characteristic of T.cells.Br/J. Haental. 50:241-245.

13.Zabrodski, PE; Germanchok, VG;Lirchok, VE and Aredako, AN, (2008) .Anticholinestrase mechanism as a factor of immunotoxicity of various chemical.

14.Exon. J.H.; Kirkvliet, N.L. and Talcot. P.A. (1987). Immunotoxicity of carcinogenic pesticides and related chemicals. J. Env. Sc. Hlth. Paste, Environ., Carcinog. Rev. 5: 73-120.

15-Wight D.G.D. (1982) Fatty liver in atlas of liver pathology. Lancaster. MTP Press Ltd. 1982; pp $95-100$.

16. Shalaby, S. M.; Farrag, A. R. and El-Saed, G. S. (2010) Toxicological potential of thiamethoxam insecticide on albino rats and its residues in some organs. JASMR, 5(2): 165-172.

17.Saleh A. A. Toxicological and histological effect of different pesticides on some blood parameters and liver tissues in rats. J. Agric. Sci. Mansoura Univ. Egypt. 1993; 18 (1): 296 - 301.

18.Massey E. D., Butler W. H.(1979). Zonal changes in the rat liver after chronic administration of phenobarbitone in ultrastructural, morphometric and biochemical correlation. Chem Biol Interact 24, 329-44.

19.Slauson D. O., Cooper B. J.(2001). Mechanism of Disease - A Textbook of Comparative General Pathology. Mosby, New York, NY; p. 122.22.Williams G. M., Iatropoulos M. J.(2002). Alteration of liver cell function and proliferation: Differentiation between adaptation and toxicity. Toxicol Pathol 30, 41-53.

20.Evans J., Lake B.(1998). The digestive system ii: The hepatobiliary system. In Target organ 
pathology. A basic text. (Turton J., Hooson J., eds.), pp. 61-97. Taylor and Francis, London.

21.Greaves, P. (2000).Histopathology of Preclinical Toxicity Studies. Interpreta-tion and Relevance in Drug Safety Evaluation. Elsevier, London, UK.

22.K. A. Ford and J. E. Casida,2008 "Comparative metabolism and pharmacokinetics of seven neonicotinoid insecticides in spinach," Journal of Agricultural and Food Chemistry, vol. 56, no. 21, pp. 10168-10175.

23.Förstermann U, Closs EI, Pollock JS, Nakane M, Schwarz P, Gath I, Kleinert H. (1994 )Nitric oxide synthase isozymes: characterization, purification, molecular cloning, and functions. Hypertension.; 23: 1121-1131.

24.El-Hawashy N. and Khedr F. Histopathological effects of calciferol on albino rat, Rattus norvegicus. J. Agric. Sci. Mansoura Univ., Egypt. 2001; 26(12): 8029-8046.

25.Newcombe, DS and Esa, AH(1992) Immunotoxicity of organophosphorus compounds.In clinical immunotoxicitym DSM Newcombe, Rosem NR; Bloon, JC ed,PP349360.Raven.Press,New York.

26.Alwan, M.J. (1996). Nocardia osteroides studies some aspect of pathogenesis. Ph. D. Thesiscollege of veterinary Miedicin- Baghdad University.

27.Taylor, P,(2006). Antichicholinestrase agent.In the pharmacological basis of therapeutic. Bruntion, LL; Laza, JS ;Parker,IC eds PP2O1-216.MCC raw-Hill, New York 